\title{
Design e atividade humana nos espaços de sociabilidade urbana: interações no Baixo Centro de Belo Horizonte
}

Design and human activity in spaces of urban sociability: interactions in the Lower Center of Belo Horizonte

QUINAUD, Paula Márcia Alves; Mestre; Centro Universitário UNA

paulaquinaud@hotmail.com

\section{Resumo}

O presente artigo constrói uma interlocução entre design e atividade humana dentro dos espaços de sociabilidade urbana e tem como estudo de caso as relações estabelecidas no chamado Baixo Centro da cidade de Belo Horizonte. Visando compreender o ser social em possibilidades, escolhas e contextos, fez-se a revisão dos conceitos sob a ótica de alguns autores, cruzamento de dados e pesquisa de campo. Ao observar o processo de inclusão sócio-territorial na área estudada e investigar a sua ressignificação e apropriação por distintos grupos sociais, foi possível pensar o papel do design como agente transformador de um lugar e perceber as dificuldades que aparecem quando são confrontadas as vocações de uso dos locais públicos e os interesses diversos de planejamento. Observou-se ainda, que nos espaços transformados em lugares sociais, também pelo design, parece lógico que muito das efetivações e pertencimentos, se dêem a partir das escolhas corretas nas decisões projetuais.

Palavras Chave: cidade; design; sociedade.

\begin{abstract}
The present article constructs an interlocution between design and human activity within the spaces of urban sociability and has as case study the relations established in the so called Low Center of the city of Belo Horizonte. In order to understand the social being in possibilities, choices and contexts, the concepts were revised from the perspective of some authors, data crossreferencing and field research. By observing the process of socio-territorial inclusion in the studied area and investigating its re-signification and appropriation by distinct social groups, it was possible to think about the role of design as a transforming agent of a place and to perceive the difficulties that appear when confronted with vocations of use of the public places and the diverse interests of planning. It was also observed that in spaces transformed into social places, also by design, it seems logical that much of the effectiveness and belongings are given from the correct choices in the design decisions.
\end{abstract}

Keywords: city; design; society. 


\section{Design e atividade humana nos espaços de sociabilidade urbana}

A vida do homem em sociedade, sua relação com o meio e com as outras pessoas nele inseridas, é partido para muito pensar. As conclusões, por mais diversificadas que sejam, tem como princípio do olhar, quase sempre, o desencadeamento das ações que aproximam ou afastam o ser social. É este o mote do presente trabalho, que se pretende um artigo de revisão que trata das inter-relações entre design e atividade humana, tendo como pano de fundo para análise, os espaços urbanos de sociabilidade e uma pesquisa de campo realizada no Baixo Centro da cidade de Belo Horizonte entre julho e dezembro de 2017. Ao se tratar de qualidade de vida, cada ser individual estabelece parâmetros e prioridades, tendo como base suas experiências pessoais, psicológicas, culturais, bem como as faltas e farturas que aparecem ao longo do tempo. No entanto, a busca pelo equilíbrio, que engloba o bem-estar físico, mental, espiritual e aspectos como família, amigos, saúde, amor, educação, trabalho, habitação, condições econômicas e algumas circunstâncias da vida, costuma ser recorrente nas definições que são apresentadas como premissas para a plena realização do indivíduo em sociedade. A satisfação dessas necessidades e as formas de sua efetivação, com vistas à felicidade, são categorizadas pela Organização Mundial de Saúde, que as identifica em seis esferas básicas: física, psicológica, de nível de independência, das relações sociais, do meio ambiente e dos aspectos religiosos. Pensar esse ser social em um dos seus espaços primeiros de significação, a rua, e sua relação com o entorno é tarefa que pode gerar muitas reflexões.

Diante de tudo que um designer pode ser, em termos de competências diversas, o design aparece também como modo de dar significado ao espaço e alçá-lo à condição de lugar. Para LÖBACH (2000) "... todo processo de design é também um processo criativo e de solução de problemas." O que diz muito quando se tem na expectativa dessa solução, que desejos e urgências sejam atendidos de maneira contínua. Ainda para o autor o trabalho do designer "consiste em encontrar uma solução do problema, concretizada em um projeto de produto [...] incorporando as características que possam satisfazer as necessidades humanas, de forma duradoura" (LÖBACH, 2001, p.141).

Perceber o modo em que as decisões projetuais, na maioria das vezes respaldadas em técnica e tecnologia, vão impactar diretamente as atividades humanas de maneira individual e coletiva, pode abrir a perspectiva para as formas de vivenciar os espaços públicos no que diz respeito ao pertencimento, exclusão e à própria cidadania. Para entender a exata medida em que esses diversos conceitos citados se entrelaçam, é necessário primeiro que se pontue o entendimento de cada um deles.

\subsection{O design do lugar}

Presente em diversas fases históricas e de desenvolvimento da sociedade, como busca da união da estética das coisas às suas funcionalidades, o design desde muito cedo, pontua escolhas e decisões. Inventar, planejar, engendrar, configurar, criar, idealizar. Por esses caminhos é que o designer desenvolve o seu processo criativo. Para um bom projeto de design é necessário empenho de tempo e pensamento, pesquisa e conteúdo. Porém, como em todos os processos de elaboração de uma atividade humana, a metodologia no design se faz premissa e é construída, a cada dia, e com cada experiência. Em alguns campos do design, os estudos metodológicos se fazem mais antigos, em outros mais escassos. Por esses princípios também, o design de ambientes 
vai buscar referenciais para desenvolver um método próprio que the possibilite maior assertividade. Ao pensar o design de modo geral, como uma atividade estratégica, técnica e criativa, voltada para a criação de uma solução, orientada por uma intenção e objetivo, eficaz para um problema, há que se ter foco no caminho a ser percorrido.

Para, contudo, se projetar design dentro de todos os paradigmas que lhe competem e diferenciam, é necessário um construto que aponte os valores e delimite a direção. Algo que respalde e gere possibilidades de argumentos e de defesas, mas que, principalmente, reflita-se no resultado ao explicar o motivo de cada escolha projetual. Sejam cores, formas, texturas, curvas e tamanhos, tudo que compõe o espaço trabalhado, justifica-se na elaboração e legitima-se em uma palavra chamada conceito. Assim pode-se dizer que um conceito é sempre portador de significado e que todo lugar é um espaço conceituado. Nesta afirmação, no entanto, encontram-se embutidas perguntas que vão permear o design de ambientes e que YI-FU Tuan colocou sob o foco da luz da experiência, ao refletir sobre o que confere identidade e aura a um lugar. Segundo o autor:

Medimos e mapeamos o espaço e lugar, e adquirimos leis espaciais e inventários de recursos através de nossos esforços. Estas são abordagens importantes, porém precisam ser complementadas por dados experienciais que possamos coletar e interpretar com fidedignidade porque nós mesmos somos humanos. (TUAN, 1983, p.05)

Ao designer de ambientes compete projetar espaços que acrescentem funções e tornem a experiência do usuário eficiente em suas mais diversas possibilidades. Para tanto é que ele deve, em seu trabalho, buscar uma largueza de olhar que contemple a investigação das nuances externas que influenciam o indivíduo, aliadas às emoções imanentes ao ser. Percebe-se que, embora o bom êxito na percepção e uso dos espaços esteja diretamente ligado a questões como usabilidade e ergonomia, para que aconteça uma leitura satisfatória, completa e real de um ambiente é essencial que o designer de ambientes promova o resgate do passado cultural por meio de signos e símbolos socioculturais para auxiliá-lo, e que permitam até mesmo explorar novas tecnologias.

É justamente o que Marc Augé explica, quando diz que, em oposição aos não-lugares, que seriam locais de passagem incapazes de agregar pertencimento, aparece o espaço antropológico que vai criar identidades e fomentar as relações interpessoais dentro de um tempo definido, possibilitando que ocorra "simultaneamente o princípio de sentido para aqueles que o habitam e princípio de inteligibilidade para quem o observa." (AUGÉ, 1994, p. 51). Para o autor, é também na identificação de uma história individual que se enriquece a experiência coletiva. No seu lugar de origem, uma pessoa vive e celebra sua existência, reside, trabalha e guarda as suas fronteiras. Segundo ele:

Nascer é nascer num lugar, ser designado à residência. Nesse sentido, o lugar de nascimento é constitutivo da identidade individual [...] o que equivale a dizer que, num mesmo lugar podem coexistir elementos distintos e singulares, sem dúvida, mas sobre os quais não se proíbe pensar nem as relações, nem a identidade partilhada que lhes confere a ocupação do lugar comum. (AUGÉ, 1994, p.53)

Nesse sentido é que antes que o designer passe a se dedicar sobre as diversas etapas de elaboração projetual, há que se concentrar, uma vez identificado o público usuário, nas lembranças e associações de aspectos culturais e emocionais que deseja imprimir ao seu objeto de trabalho. Se a proposta é uma abstração da realidade física, a criação de uma nova identidade ou apenas uma revitalização a partir de referências conhecidas, o fato é que o objetivo vai sempre 
estar voltado para a elaboração de projetos que consigam promover a expressão da individualidade humana do modo mais prazeroso e sensível. A assertividade ao se imprimir um significado a partir de uma abordagem conceitual, contudo, vai estar intrinsecamente respaldada pelo rigor e precisão no levantamento e trato das informações que caracterizam os atores envolvidos.

\title{
1.2 Os contornos da atividade humana
}

Antes de se compreender o que seja atividade humana, vale trazer a ideia de atividade dentro da premissa de se colocar algo em movimento, ação que tem como fim uma realização. Quando a dimensão humana atrela-se à atividade, seus contornos tornam-se mais extremados e menos etéreos. Segundo LEONTIEV (2014, p.2) "atividade é uma unidade não-aditiva da vida material, corpórea, do sujeito material. Em um sentido estreito, i.e., no plano psicológico, é uma unidade de vida, mediada pela reflexão mental, por uma imagem, cuja função real é orientar o sujeito no mundo objetivo." Isso traz a percepção tanto da medida em que ela pode moldar a maneira individual ou coletiva de se portar, quanto da capacidade que atribui a esse ser de interferir no meio. Como um processo de modificação do mundo e de si, estabelece sempre relações imanentes entre o indivíduo e o ambiente em que se insere, ainda para Leontiev:

\begin{abstract}
Não importam as condições e formas nas quais a atividade do homem procede, não importam quais estruturas adquire, não pode ser considerada como algo extraído de relações sociais, da vida da sociedade. Apesar de toda sua diversidade, todas as suas características especiais, a atividade do indivíduo humano é um sistema que obedece o sistema de relações da sociedade. Fora destas relações, a atividade humana não existe. (LEONTIEV, 2014, p.2)
\end{abstract}

No entanto é preciso que se esteja sempre alerta diante da complexidade dessas correspondências que se estabelecem quando se tem o sujeito na transformação do entorno e transformado, em via de mão dupla, dentro do contato direto com o contexto, com os objetos que o cercam e indo além do que se pode perceber. Pautada por contradições e pela tentativa de satisfazer necessidades, a atividade humana localiza-se em tempo e espaço determinados, tem motivação real ou ideal e é balizada por regras sociais, pela divisão social do trabalho e por signos, linguagem e utensílios disponíveis em um dado local. Dentro de uma dimensão externa e física ou interna e psíquica, atividade e homem vão se dimensionando e efetivando em saberes e afetos experimentados no vínculo com a natureza, com os objetos e com outras pessoas. E é justamente aí que o design aparece como meio de instrumentalização desse homem, na forma dos prolongamentos corporais criados, dos equipamentos e ajustes no ambiente que melhoram a maneira de trabalhar e transformar o meio.

Além dos utensílios, ferramentas, instrumentos, existem outras variáveis que vão balizar os limites e possibilidades de uma atividade humana, como as experiências e conhecimentos acumulados pelo sujeito da atividade, os procedimentos necessários à ação e a conformação da sociedade em questão e suas relações. Igualmente relevantes e demarcadoras, vão compor a dinâmica comportamental do homem.

\subsection{Inter-relações nos espaços de sociabilidade urbana}

Felicidade, tendência, necessidade, vontade, capacidade, arte de se viver em sociedade. Diversos substantivos podem trazer o entendimento de sociabilidade na imagem do ser individual agregado por pompa ou circunstância a um grupo de pessoas que compartilhe costumes, 
propósitos, gostos e preocupações em um estado de colaboração mútua. E entendendo como urbano tudo o que tem uma relação direta com a vida na cidade, bem como com os indivíduos que nela fruem, tem-se na combinação dos dois termos a deixa, fundamento, aparato para se delinear o palco primeiro de produção das atividades humanas comunitárias, da cidadania.

Cada cidade possui uma identidade própria, ditada pelas combinações da morfologia territorial, aspectos históricos, culturais, econômicos, conformação da arquitetura e do design, condições ambientais e das relações sociais que se estabelecem entre as pessoas e o entorno. Essas dimensões simbólicas e materiais ajudam a construir, através de confrontos ou interações nos espaços públicos ou privados, os contornos da vida em sociedade.

Promover uma vida digna ao cidadão implica o acesso aos direitos civis, à educação e às oportunidades de trabalho, assim como o acesso irrestrito à própria cidade. Essas conquistas não se dão em curto prazo, mas são construídas a partir de um amplo decurso de melhoria contínua da qualidade de vida de um território. É nesse conceito, amplamente utilizado por governos, pelo terceiro setor e no meio acadêmico, que reside o desafio, os acertos e ganhos, mas também a possível exclusão. Para Montenegro Gómez (2002), o desenvolvimento social é um poderoso mobilizador dentro do discurso socioeconômico e político vigente, muitas vezes usado a serviço de diretrizes das políticas públicas e dos anseios da iniciativa privada, orbitando ao redor desse objetivo supostamente benéfico para toda a sociedade. Contudo, essa mesma idéia de desenvolvimento, usada e difundida, inscreve-se "plenamente ao corpo ideológico do capital, servindo como instrumento dinamizador da sua expansão e da acumulação." Ainda para ele:

\begin{abstract}
Sem constituir-se numa proposta homogeneamente concebida, o desenvolvimento local, reforça a dinâmica acumulativa do capital e avança nas estratégias de controle social. 0 reformismo que propõe o desenvolvimento local através da consolidação de uma comunidade plural, fortalecida pelo consenso e a participação, não abala o status quo de uma relação capital $x$ trabalho dominada pelo primeiro (MONTENEGRO GÓMEZ, 2002, p.20).
\end{abstract}

Pensar à luz da atualidade dessa concepção é premissa para compreender e explicar como se dá a produção do espaço urbano contemporâneo. Partindo desses pressupostos, pode-se dizer que a atuação do design na conformação dos lugares citadinos, e toda alteração que sofrem ao longo das épocas e dos governos, impacta não só na leitura, percepção e consequente vivência, como define a medida das restrições, dos pertencimentos e de toda gama de associações que se dão nos seus espaços de coexistência humana. Trazer o design, para esse contexto, como meio de instrumentalização das ações individuais e inter-relações coletivas no convívio urbano, provoca um alinhamento de ideias e faz chegar ao ponto central desse trabalho.

Dentro dos preceitos da análise de fatores externos ao ser, que contribuem para uma maior integração entre o indivíduo e o espaço construído, está a busca da identidade no design por meio das culturas. Para se encontrar referências que possibilitem uma identidade local há que se trabalhar o aspecto humano. Para MORAES (1997), entre os principais pontos a serem observados, estão:

os aspectos culturais que dizem respeito ao comportamento humano, os aspectos semiológicos, semânticos e psicofisiológicos (cognitivos, psicológicos e subjetivos) que envolvem a concepção de produtos. (...) o design se aproxima ainda mais neste final de século das ciências sociais, da sociologia, da antropologia e da filosofia, em busca de antecipar as necessidades reais dos usuários do futuro (MORAES, 1997, p.56). 
As disposições de configuração espacial urbana, tendo no design os procedimentos adotados para uso e desenvolvimento das ações, são tratados aqui como meios de estreitar as conexões entre os indivíduos da sociedade civil e seus modos de operar na cidade. Para melhor perceber a relação estabelecida entre paisagem e os fruidores, há que se analisar as atividades exercidas individual ou coletivamente, mas também identificar as conformações físicas, decisões projetuais, equipamentos públicos, objetos construtivos, materiais especificados, mobiliários urbanos, relações ergonômicas, enfim, a forma real e concreta em que figura o seu cenário e as apropriações de seus espaços pelos grupos sociais.

Todo esse panorama de vínculo e subjugo se encontra nos espaços de sociabilidade urbana, onde os mecanismos que se apresentam como implementadores dos relacionamentos e balizadores das posturas, de novo cedem aos ditames da hora e balanços dos mercados e muitas vezes aos modismos. Se por um lado os interesses sociais delimitam a direção, funções e a velocidade dos avanços tecnológicos, que acabam definindo um sistema social, por outro as mudanças, adequações, atualizações se darão sempre pela lógica da manutenção desse próprio sistema. Daí chega-se em um arcabouço crítico, onde a existência parece fadada a ciclicamente se moldar ao interesse do momento.

Um desdobramento possível a variar essa realidade aparece na busca dialógica pelo consenso na fala de Habermas quando traz a forma privada de valorização do capital aliada ao modo de distribuição das compensações sociais dando lugar a "um progresso quase autônomo da ciência e da técnica, do que, independe de fato a outra variável mais importante do sistema, a saber, o crescimento econômico." (HABERMAS, 1983, p.73). Para tanto há que se fazer claro o conjunto de condicionantes para a efetivação, por hora idearia, desse processo:

\begin{abstract}
Certamente, esta intenção tecnocrática não está realizada em parte alguma nem sequer nos seus passos iniciais, mas serve, por um lado, como ideologia para uma política dirigida à resolução de tarefas técnicas que põe entre parênteses as questões práticas; e, por outro lado, incide de quaisquer modo em certas tendências evolutivas que podem levar a uma lenta erosão do que chamamos o marco institucional. A dominação manifesta do Estado autoritário retrocede perante as coações manipulatórias da administração técnicooperativa. A implantação moral de uma ordem sancionada e, assim, da ação comunicativa que se orienta por um sentido linguisticamente articulado e que pressupõe a interiorização de normas, e dissolvida numa amplitude cada vez maior por modos de comportamento condicionados, enquanto as grandes organizações como tais se apresentam cada vez mais com a estrutura da ação racional dirigida a fins. (HABERMAS, $1983, \mathrm{p} .75)$
\end{abstract}

Vale ainda inserir a prática tecnológica no contexto urbano a partir das interferências que pode sofrer quando atrelada a conjuntos que, dentro da comunidade, exerçam um papel seletivo. Sejam eles, por exemplo, grupos religiosos, movimentos ambientalistas ou setores produtivos, influenciam na produção de novas tecnologias e conformação do design, o que acaba por impactar no instrumental para os usos dos espaços e relacionamentos nas cidades. Para esse entendimento Trigueiro (2008) inclui o conceito de prática tecnológica como o processo de transformação de uma matéria-prima determinada cujo produto é típico do sistema em que se insere. E ainda, uma vez existindo tantas práticas quantos forem os sistemas diferenciáveis de transformação, vai se estabelecer um conjunto de práticas, em que a prática social funciona como a sua unidade. "Neste sentido, não há prática em geral, mas práticas determinadas e singulares: a prática econômica, a prática política, a prática científica, a prática tecnológica." (TRIGUEIRO, 2008, p. 93). 
Partindo da ideia de que a realidade social é composta por um conjunto de práticas articuladas entre si, mas com uma relativa autonomia na estrutura social, parece possível pensar o design em termos de inovações de práticas sociais que favoreçam o modo em que se dão os processos colaborativos, desenvolvam a cidadania e estimulem o empoderamento em novas relações sociais nos espaços de sociabilidade urbana. Algumas dessas dinâmicas são observadas no estudo de caso a seguir.

\section{Interações no Baixo Centro de Belo Horizonte}

A configuração e as constantes transformações urbanas nas grandes cidades se desenvolvem, criando cenários que interferem diretamente na vivência das pessoas e na formação da cidadania. Nos espaços públicos, semipúblicos e privados se estabelecem as relações de participação social, política e é onde a vida local representa o seu papel cotidiano. É preciso que se compreenda a cidade em suas nuances, melindres e imposições. Essa leitura nem sempre é coisa fácil, uma vez que existe um processo dinâmico e incessante de reorganização.

Ao pensar a cidade, buscamos compreender o presente e, em certa medida, as possibilidades de um futuro. Isso porque ambos, passado e futuro, são construções que se consolidam no agora, e que vivenciamos a todo o momento ao caminhar pela cidade. Pensar o espaço vivido e compreender as relações que nele são construídas constitui uma tarefa infinita, já que o tecido urbano adquire novas tramas, sempre feitas, desfeitas e refeitas (NASCIMENTO, 2012, p. 21).

Em Belo Horizonte, essa lógica não é diferente. A capital mineira, que nasceu no contexto do ideal republicano como uma cidade planejada e construída em três anos, acenou desde o início com ares de modernidade, ordenamento do espaço e uma lógica funcional eficiente. Jovem e aberta ao novo, a cidade acolheu desde sempre diversas formas de arte e arquitetura que foram mudando as paisagens e deixando marcas estéticas e temporais. Para preservar a história e fazer arranjos e conexões entre os marcos da tradição e a necessidade de modernização, deu-se a implantação de diversos processos de adequação e transformação urbana ao longo dos anos. E, como acontece em todas as grandes cidades do mundo, tais ações impactaram e selecionaram os atores.

Segundo Moreira (2008, p.36), foi, sobretudo, a partir de meados dos anos 1980 que as formas de intervenção na região central de Belo Horizonte começaram a se impor de modo mais nítido e com maior visibilidade. Pautada no discurso da importância histórica da região para a memória da cidade e "da necessidade de melhoria das condições de seus espaços físicos", percebe-se uma confluência entre as intenções de valor simbólico e de recuperação física de um espaço considerado degradado.

Essa nova postura ante as nuances dos espaços públicos, acaba por acompanhar tendências internacionais de revalorização dos centros históricos de grandes cidades e começam a provocar transformações significativas neste cenário. No entanto, é a partir de meados da década de 1990, quando o abandono e desvalorização imobiliária do Hipercentro aparecem como questão "recorrente tanto nos discursos e projetos do poder público quanto na mídia da capital, que os projetos de intervenção - física e simbólica - na região se afirmam de forma mais sistêmica e concreta" (MOREIRA, 2008, p. 37).

Dentre as diversas experiências de reconfiguração urbana ocorridas em Belo Horizonte, uma vem chamando a atenção e tem se tornado objeto para alguns estudos: a remodelação do 
Baixo Centro. Apontado por alguns autores como um local onde ocorreram várias tentativas de melhoria da qualidade ambiental, infraestrutura e higienização, essa região da cidade mescla a alteração da paisagem urbana em fases de preservação do centro histórico e degradação. Concentrada em uma área do Hipercentro, recebeu essa nomenclatura, segundo Trevisan (2012, p. 48), "a partir de meados do século $X X$, quando se acentuou o processo de distinção socioespacial visível no interior do próprio centro da cidade desde os primeiros anos de sua história".

Inserido em uma área que abrange o entorno da Praça Sete e da Praça da Estação, vem a ser um dos espaços privilegiados por essas intervenções, sendo que, segundo Moreira (2008),

recebe atenção especial dos chamados projetos de revitalização urbana, os quais destacam a dimensão simbólica deste espaço e investem maciçamente em seus aspectos histórico-culturais e na produção, afirmação e legitimação de uma memória da/para a cidade (MOREIRA, 2008, p.37).

Entendido assim como um lugar ora de trânsito e de passagem, ora de convívio e ainda de permanência e moradia, o Baixo Centro de Belo Horizonte é o cenário de uma pesquisa, realizada entre julho e dezembro de 2017, que buscou analisar a relação dos diversos atores com o entorno, na perspectiva da objetivação das interações sociais, bem como no trato da subjetivação das atividades humanas. Ao observar um lugar específico, percebem-se os sujeitos e as suas bagagens subjetivas, atuando como agentes transformadores e a atividade humana, balizada na leitura individual dos instrumentos, equipamentos e do entorno, aparecendo como uma forma de organização das relações sociais.

É de acordo com essa ideia do relacionamento humano dentro dos espaços de sociabilidade urbana e de como o design atua nos processos de apropriação desses espaços que a pesquisa se desenvolveu. Para que fosse possível estabelecer um olhar mais pontual, descritivo e analítico do processo de ressignificação do Baixo Centro de Belo Horizonte e compreender o ser social ali presente, nas suas possibilidades, escolhas, contextos e implicações com o meio em que se insere, ao longo da pesquisa, foi se fazendo necessário um recorte mais delicado e preciso. Alguns locais, eleitos pela própria população como icônicos ou apropriáveis e que passaram por intervenções, surgiram como destaque e centro de interesse. A Praça da Estação; o Viaduto de Santa Tereza; o complexo do Boulevard Arrudas; além de algumas vias do entorno imediato; equipamentos públicos e em especial o mobiliário urbano foram protagonistas da investigação, como demonstrado no mapa abaixo. 
FIGURA 1 - Baixo Centro de Belo Horizonte - Área pesquisada

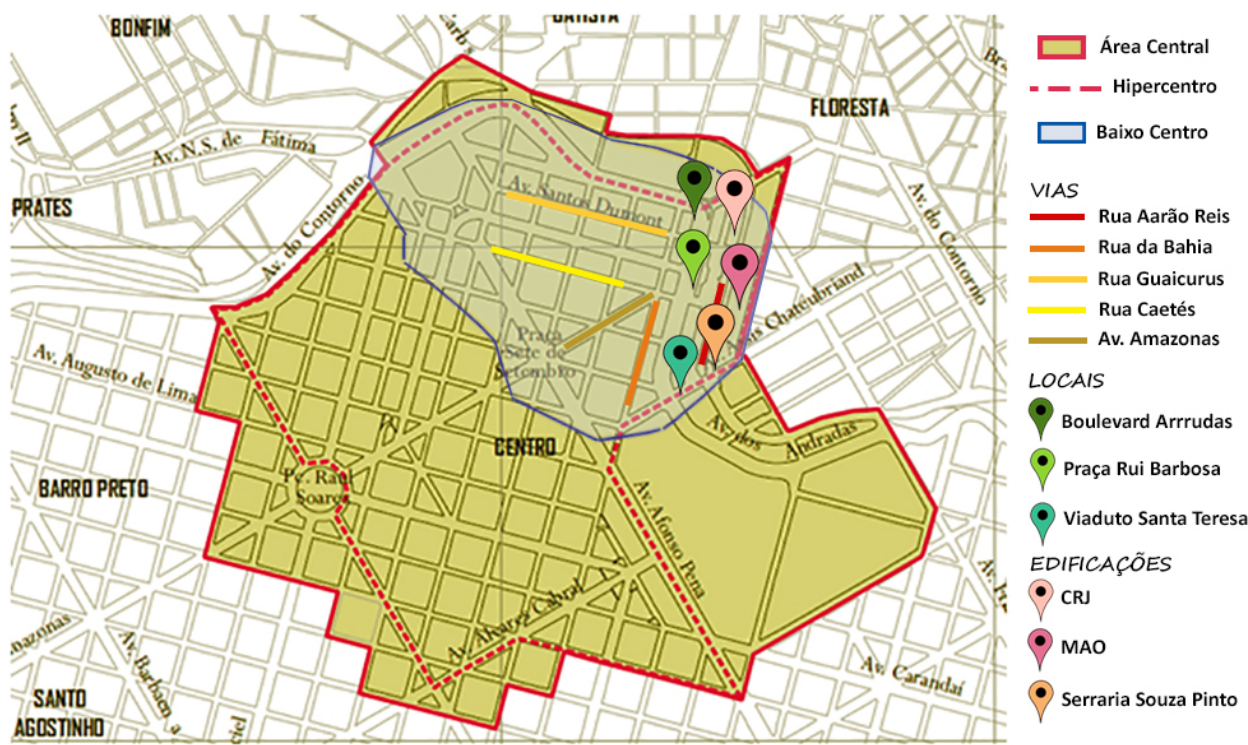

Fonte: Elaborado pela autora.

Abrigos de ônibus, acessos ao metrô, bancos, lixeiras, cabines telefônicas, caixas de correio, postes de sinalização e de iluminação, semáforos, relógios, esculturas, fontes, hidrantes, painéis, quiosques, playgrounds são exemplos de mobiliário urbano presentes no dia a dia de todos que fruem o espaço da cidade. Entendendo o espaço urbano público como algo que deve ser em primazia apropriável e, como já citado antes, de acesso irrestrito (LYNCH, 2006), tem-se no seu contexto a inclusão de uma série de elementos que vão complementar o conjunto de edificações que conformam a cidade.

Dentre os vários olhares acerca do que seja mobiliário urbano, um dos que mais se aproxima do pensamento tratado aqui está em Mourthé (1998), que o entende como produto de uso público, fundamental à paisagem urbana e que contribui para a qualidade de vida e bem-estar das pessoas. Com o objetivo de auxiliar e dar conforto aos usuários, o mobiliário urbano ainda "compõe o ambiente no qual está inserido e faz parte do desenho urbano das cidades, interagindo com seus usuários, com o contexto sociocultural e ambiental" (MONTENEGRO, 2005, p. 29), além de ser muitas vezes "o principal responsável pela imagem dos lugares" (KOHLSDORF, 1996, p.160161). Nesse sentido, destaca-se o seu design e a sua utilidade prática, mas também se salienta a forma como pode imprimir ao meio urbano uma identidade própria por meio do modo em que figura a sua participação na história da cidade.

Dessa maneira, estudam-se aqui alguns pontos determinados dessa região, no que tange ao impacto da sua conformação espacial nos processos de pertencimento e inclusão dos diversos grupos locais. Magnani (2009) traz a ideia da necessidade de aproximação, adotando uma postura "de perto e de dentro", como forma de investigação de uma vivência diária citadina, que propicia a construção de um olhar que desvende toda uma gama de relações e tensões cotidianas, que se estabelecem entre os vários agentes que significam a cidade. 


\subsection{Pertencimento e depredação: o relacionamento com a coisa pública}

Quando se pensa em depredação, a regra parece simples: só se estraga o que não é seu... Voluntariamente. Se for meu, me pertence, eu conservo. Mas antes das coisas que estão nos lugares pertencerem às pessoas, os próprios lugares devem pertencer às pessoas. $E$ esse é o ponto central de tudo: o direito ao espaço público. Direito de ir, vir, parar, encontrar, estar, manifestar. É essa a base da afirmação de todas as identidades no espaço público. E no espaço público urbano de uma maneira potencializada. É nesse momento que a conformação física das cidades, dentro das premissas do design, mostra-se um meio de incluir pessoas. Durante esta pesquisa de campo, algumas dessas dinâmicas puderam ser notadas.

Ao observar, por exemplo, os modos de relacionamento na Praça da Estação, a situação de grande ocupação sempre se repetiu. O cenário encontrado, no entanto, foi de interação total dos usuários eventuais com o entorno, e parcial com os habitantes locais, na maioria pessoas em situação de rua. Pode-se perceber um uso efetivo dos equipamentos urbanos, bem como uma boa utilização dos espaços comuns. Nesse sentido, pareceu acertada a opção projetual pela criação de fontes secas e embutidas no piso, que geram uma grande esplanada e cuja organização espacial permite utilizações diversas e mesmo estimula essas diferentes possibilidades de uso.

Em termos de conservação percebe-se um nível alto de intervenção nos prédios e demais equipamentos, principalmente ao longo da Rua Aarão Reis. O que se tem são tentativas de interação urbana, como se cada milímetro do seu espaço precisasse urgentemente ser ocupado. Placas de trânsito, bancos, telefones, esculturas, portas, coberturas, fachadas inteiras... tudo é território demarcado.

FIGURA 2 - Rua Aarão Reis - setembro 2017

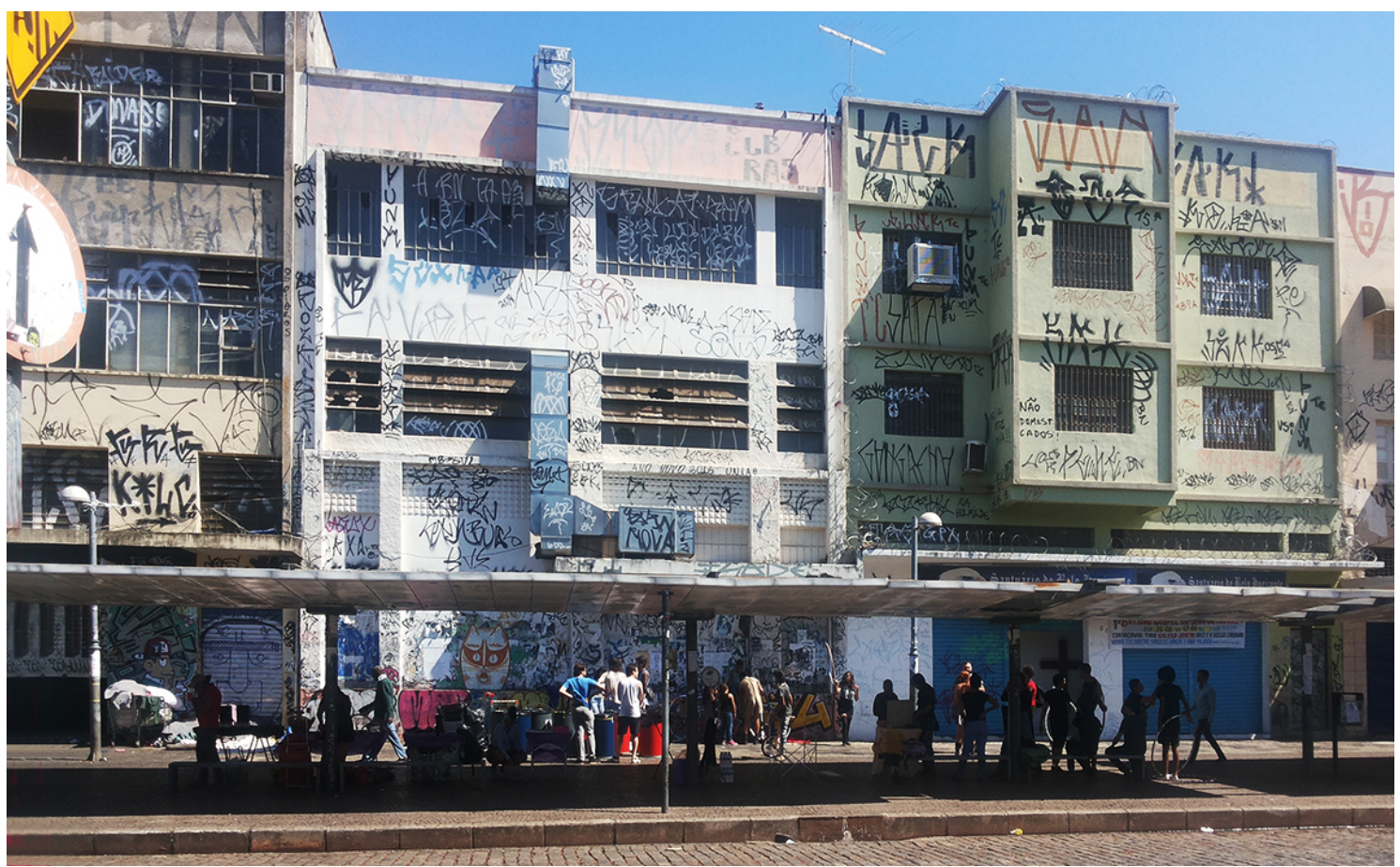

Fonte: Foto arquivo pessoal. 
O que para muitos é um cenário caótico com pichação, lixo e depredação, para tantos é uma forma legítima, e talvez a única possível de apropriação do espaço público em uma estética da resistência. Incômodos, ruídos propositais, rasuras na leitura da cidade tem o porquê sinalizado no depoimento de um pichador detido por vandalismo em Porto Alegre: "eu picho quando estou feliz, quando estou triste, picho por amor, por ódio, para homenagear alguém e também para denunciar algo que está errado" (MAGS apud PIZZATO, 2013, p. 60). Na Aarão Reis, vários motivos podem ser aventados. Se descaso das políticas públicas que não se voltam para lugares ocupados por classes mais pobres, se reação de pessoas que não percebem o ambiente como seu, o fato é que parece ter muita gente que precisa externar muita coisa. Entre vidraças quebradas, grafites, letras, traços quase hieroglíficos, não há como negar, tem muita vida pulsando ali.

Em relação ao mobiliário urbano de uma cidade como Belo Horizonte, os números são sempre bastante altos. Não é difícil que se encontrem dados como "todos os anos, a administração municipal gasta cerca de $\mathrm{R} \$ 2$ milhões para reparar os danos causados ao patrimônio da cidade"; ou "em 2015 o município gastou cerca de $\mathrm{R} \$ 30$ mil apenas com a limpeza do obelisco da Praça Sete"; ou "mais de 10 mil lixeiras foram consertadas ou trocadas em BH em 2015"; ou ainda "com o objetivo de sensibilizar o cidadão a descartar corretamente o lixo, cerca de 22 mil lixeiras em Belo Horizonte estão ganhando um novo visual [com] novos adesivos [...] sob o mote Eu jogo limpo com BH. Eu jogo o lixo aqui" ${ }^{\text {. }}$.

FIGURA 3 - Praça da Estação - Mobiliário Urbano presente na região - ago. 2017
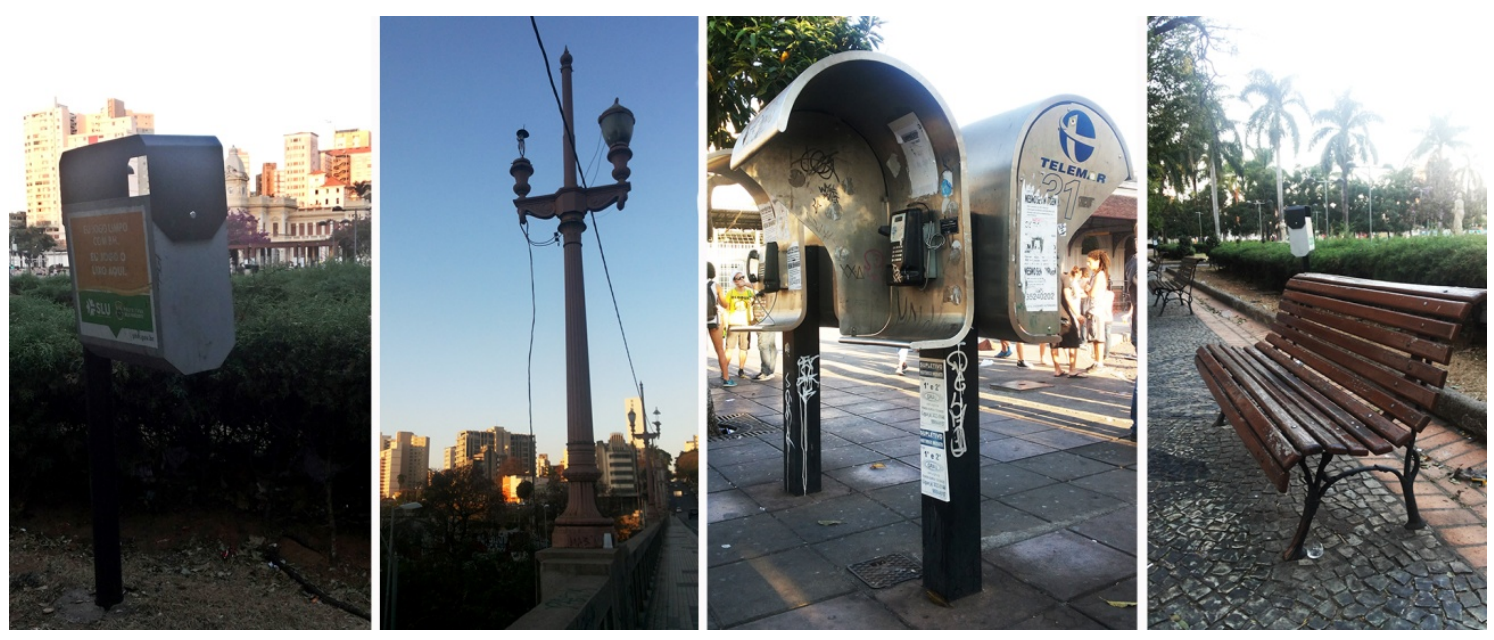

Fonte: Foto arquivo pessoal.

Realmente ao se observarem os equipamentos instalados no Baixo Centro de Belo Horizonte, percebe-se a importância deste "sensibilizar o cidadão". Na maioria das vezes, sem um padrão definido em termos de finalidade do mobiliário ou do local em que está inserido, descuido, maltrato e depredação são ações recorrentes. Ao se pensar esse cenário dentro dos preceitos do design, na identificação correta de um briefing ou de envolvimento com a comunidade, tem-se uma pista de por onde anda o descompasso. Em reportagem do Jornal Hoje em Dia de 11 de maio

2 Dados dos jornais ESTADO DE MINAS, caderno Gerais, abr 2016. Disponível em: https://www.em.com.br/app/noticia/gerais/2016 e JORNAL HOJE EM DIA, Caderno Horizontes, 11 mai. 2016. Disponível em: http://hojeemdia.com.br/horizontes/por-ano-pbhdesembolsa-r-2-milh\%C3\%B5es-para-reparar-depreda\%C3\%A7\%noC3\%B5es-ao-patrim\%C3\%B4nio-p\%C3\%BAblico-1.383473 Acesso em: 26 set. 2017. 
de $2016^{2}$ sobre danos ao patrimônio público, o urbanista Sérgio Myssior ressalta que "uma maior participação da população nas decisões de requalificação do espaço público ajudaria a reduzir as depredações dos equipamentos". Para ele, existe um senso comum de que não vale a pena o investimento em espaços públicos devido aos equipamentos serem frequentemente depredados. Mas também alerta que na medida em que se "insere a sociedade como protagonista do pensar, ela aumenta o senso de pertencimento e, com isso, caem drasticamente os problemas relacionados ao vandalismo, porque a população se enxerga no resultado". Outro ponto interessante que Myssior aborda é o fato de que o design do objeto deve levar em conta mais do que a resistência, e de que a cidade precisa desenvolver estratégias para aumentar a vitalidade de equipamentos, como bancos de praças, lixeiras, placas e aparelhos de ginástica. Segundo ele, "se o poder público aproximar o cidadão da participação, a segurança da cidade fica relacionada aos olhos da rua".

Na relação direta com o entorno, em especial com o mobiliário urbano, percebe-se no local o emprego ora usual, ora adaptado às necessidades do momento. Bancos, por exemplo, se fazem de bancos, mas também camas, mesas e varais para secar a roupa. A relação entre as pessoas em situação de rua e o mobiliário urbano que aparece ali, desperta a atenção e é estudada em diversos locais do mundo. O que chama a atenção há algum tempo é o que os pesquisadores chamam de "design ou arquitetura defensivos", que consiste na instalação de "dispositivos públicos que atuam como dissuasores para os moradores de rua" (WALSH, 2017, não paginado).

De regadores no piso a pinos metálicos na calçada, na cidade moderna aparecem técnicas defensivas e aparatos urbanos que desencorajam o uso dos espaços por pessoas em situação de rua ou mesmo são concebidos para dissuadir a pernoite. Na maioria das vezes, escondidos atrás da justificativa da funcionalidade, em alguns casos chegam a aparecer de forma grotesca, como na cidade de Angouleme, sudoeste da França, onde foram instaladas grades em volta de bancos de rua para impedir que fossem utilizados para dormir. Hoje por aqui se não são percebidos esses extremos do mobiliário urbano usados como ferramenta para destratar os habitantes mais vulneráveis da cidade, também não se nota uma contraparte inclusiva e humana, com foco na percepção social da questão. Abrigos móveis, armários de roupa coletivos e bibliotecas itinerantes são exemplos de equipamentos urbanos que poderiam estar presentes e imprimir um direito à cidade para aqueles que não têm escolha senão estar lá (WALSH, 2017, não paginado).

Nesse sentido é que se pode perceber o Baixo Centro de Belo Horizonte como um local cuja conformação e produção contínua, por vezes espontâneas do espaço, ajudam a promover uma experiência complexa e intensa de cidade. Ao acolher um público muito diversificado, entre tensões sociais, dissonâncias e confluências, reafirma sua vocação como cenário de intervenções e eventos culturais onde todos os grupos são bem vindos. É aí que as escolhas projetuais, materiais e formas de alguns equipamentos públicos, que parecem não convergir nessa mesma direção receptiva e simbólica, contribuem para que se instaure a depredação - ou muitas vezes apropriação.

3 JORNAL HOJE EM DIA, Caderno Horizontes, 11 mai. 2016. Disponível em: http://hojeemdia.com.br/horizontes/por-ano-pbhdesembolsa-r-2-milh\%C3\%B5es-para-reparar-depreda\%C3\%A7\% C3\%B5es-ao-patrim\%C3\%B4nio-p\%C3\%BAblico-1.383473 Acesso em: 26 set. 2017. 


\section{Considerações finais}

Muitas dificuldades aparecem quando se confrontam as vocações descentralizadas e espontâneas de uso dos lugares públicos e as diretrizes estabelecidas pelos projetos de design e planejamentos propostos para os espaços de coletividade. A acomodação desses impasses vão exigir um processo dialético constante entre os responsáveis pelas políticas contemporâneas de revitalização urbana e de patrimônio cultural, os designers e agentes promotores da configuração dos espaços e os seus fruidores. As formas como as cidades são resignificadas e apropriadas, ou não, cotidianamente pela população local ou agregada, estão muitas vezes vinculadas aos ruídos nessa comunicação.

Nesse todo de ideias que se cruzam, chega-se ao ponto do recomeço, retorno, processo, retoma-se Löbach (2000), quando diz que a criatividade do designer se manifesta quando este, baseando-se em seus conhecimentos e experiências, for capaz de unificar determinadas informações com um problema, estabelecendo novas relações entre eles. Entender que a medida das intenções e ações do projeto de um espaço urbano que ignora a memória do lugar histórico ou práticas culturais ali existentes, acarreta uma reação direta nos atores fruidores desse local, já é meio caminho para se conseguir o olhar que se espera do bom design.

Conceitos, definições, filosofias e estruturações a parte, os aspectos aqui referidos ora fundem-se, ora só se aproximam e muitas vezes se distanciam. Se complementam e encerram num contínuo entrecortado por premissas e significados. Linhas literalmente escritas, arbitrariamente traçadas, sutilmente determinadas... Espaços que se deviam libertariamente oferecidos, persuasivamente apropriáveis, espantosamente redescobríveis. Mas que nem sempre se efetivam. Caminhos. Só caminhos. Absolutamente caminhos percorríveis. Caminhos de pensar, de ocupar, de se ver, de buscar caminhos. Caminhos que são frutos dos caminhos trabalhados por métodos de projeto, que vão lhes atribuir sempre leitura e significado.

Oferecer a esse homem essencial lugares de convivência acessíveis e que the disponibilizem um instrumental para, junto a outros seres essenciais, poder exercer sua objetivação primeira, assim como, de maneira prática efetivar o trato de suas subjetividades, é um dos presumíveis ganhos ao se voltar o olhar sobre as possíveis leituras que se imprimem aos equipamentos e espaços sociais.

"...Tudo o que sonho ou passo, o que me falha ou finda, É como que um terraço Sobre outra coisa ainda. Essa coisa é que é linda. Por isso escrevo em meio

Do que não está ao pé, Livre do meu enleio, Sério do que não é. Sentir? Sinta quem lê!" 


\section{Referências}

AUGÉ, Marc. Não-lugares: introdução a uma antropologia da supermodernidade, Papirus. Campinas: 1994.

HABERMAS, Jürgen. Técnica e ciência como ideologia, in: W. Benjamin, M. Horkheimer, T. W. Adorno e J. Habermas. Textos Escolhidos, Abril Cultural. São Paulo: 1983.

KOHLSDORF, Maria Elaine. A apreensão da Forma da Cidade. Brasília: Editora Universidade de Brasília, 1996.

LEONTIEV, Alexei. Atividade e consciência, in: Dialectus, ano 2, n. 4, jan.-jun. 2014, p. 184-210. São Paulo: 2014

LÖBACH, Bernd. Diseño industrial, G.G. Barcelona: 2000.

LÖBACH, Bernd. Design Industrial: Bases para a configuração dos produtos industriais, Edgard Blücher. Rio de Janeiro: 2001.

LYNCH, Kevin. A imagem da cidade. São Paulo: Martins Fontes, 2006.

MAGNANI, José Guilherme Cantor. Etnografia Urbana. In: FORTUNA, Carlos; LEITE, Rogério Proença (Orgs.). Plural de Cidade: novos léxicos urbanos. Coimbra: Almedina, 2009.

MONTENEGRO, Glielson. A produção do mobiliário urbano em espaços públicos: o desenho do mobiliário urbano nos projetos de reordenamento das orlas do RN. Dissertação (Mestrado). Universidade Federal do Rio Grande do Norte, Natal, 2005. Disponível em: < http://bdtd.ibict.br/> Acesso em: 28 set. 2017.

MONTENEGRO GÓMEZ, Jorge. Crítica ao conceito de desenvolvimento, in: Pegada Eletrônica. Presidente Prudente:2002

MORAES, Anamaria. Usabilidade de Interfaces, interação humano-computador, arquitetura da informação. In : USIHC. Anais. Rio de Janeiro, LEUI / PUC. Rio: 2003.

MOREIRA, Corina Maria Rodrigues. Patrimônio cultural e revitalização urbana: usos, apropriações e representações da Rua dos Caetés. Belo Horizonte. Dissertação (Mestrado). 143f. Pontifícia Universidade Católica de Minas Gerais, Programa de Pós-Graduação em Ciências Sociais, 2008.

MOURTHÉ, Cláudia. Mobiliário Urbano. Rio de Janeiro: 2AB, 1998.

NASCIMENTO, Alexandra. Mundos em miniatura, espaços de celebração: Sociabilidade e consumo nas galerias do hipercentro de Belo Horizonte. Tese (Doutorado). Pontifícia Universidade Católica de Minas Gerais, Programa de Pós-Graduação em Ciências Sociais. Belo Horizonte, 2012.

TRIGUEIRO, Michelangelo Giotto Santoro. A prática tecnológica, in: Teoria \& Pesquisa, v. XVII. São Paulo: 2008.

TUAN, Yi-Fu. Espaço e lugar: a perspectiva da experiência, Difel. São Paulo: 1983.

WALSH, Niall Patrick. Quão agressiva pode ser a arquitetura em relação ao espaço público e aos moradores de rua. Arch Daily, mar., 2017. Disponível em: https://www.archdaily.com.br /br/867618/quao-agressiva-pode-ser-a-arquitetura-relacao-ao-espaco-publico-e-aos-moradoresde-rua Acesso em: 23 nov. 2017. 